\title{
Wheelchair Facilities Recommendation at Gambir Station
}

\author{
Fermanto Lianto $^{1 *}$ Eddy Supriyatna ${ }^{1}$ William $^{2}$ Fanny Budiyanto ${ }^{2}$ \\ ${ }^{1}$ Lecturer of Master of Architecture, Universitas Tarumanagara, Jakarta, Indonesia \\ ${ }^{2}$ Student of Master of Architecture, Universitas Tarumanagara, Jakarta, Indonesia \\ *Corresponding author. Email: fermantol@ft.untar.ac.id
}

\begin{abstract}
Public facilities that do not meet wheelchair users' needs will prevent wheelchair users from fully participating in social life. Whereas, based on Indonesian Law No. 8 of 2016, every citizen should have the same rights and obligations to obtain a decent living. As one of the largest Railway Stations in Jakarta, Gambir Station should have facilities that can accommodate the needs of all passengers. Nonetheless, based on the previous research, some facilities did not meet the needs of wheelchair users, one of which was mobility facilities. Accordingly, the researcher will discuss mobility facilities' problems and provide recommendations suitable for wheelchair users' needs. The data collection method used was participated-observation and interview. Next, these data will be analyzed using the directed content analysis approach based on reference theories and synthesized into recommendations for mobility facilities that suitable for wheelchair users. The results are supposed to be implemented at Gambir Station and become a reference for other stations in Indonesia to facilitate wheelchair users' accessibility.
\end{abstract}

\section{Keywords: Exploring, Facilities Recommendation, Gambir Station, Wheelchair}

\section{INTRODUCTION}

Every citizen has equal rights and obligations to obtain a decent living [1]. However, disabilities have not yet felt the equality of rights. Many public facilities have not considered the needs and convenience of disabilities, especially wheelchair users [2]. This problem makes it difficult for wheelchair users to access public facilities, so they cannot participate wholly in social life [3]. Whereas in Indonesian Law No. 8 of 2016 concerning Persons with Disabilities has set equal rights and opportunities for disabilities towards a prosperous, independent, and nondiscriminatory life [4].

As one of the most widely used public facilities [5], Railway Station should provide facilities that can accommodate all the needs of passengers, especially at large stations such as Gambir Station. However, based on the research results conducted by researchers in 2019, researchers found that Gambir Station did not accommodate the needs of wheelchair users [6], because wheelchair users were still having difficulty accessing facilities at Gambir Station, especially the lack of attention to mobility facilities for wheelchair users

Consequently, in this study, researchers will discuss the mobility problems faced by wheelchair users at Gambir Station. The results achieved in this study are to provide recommendations for mobility facilities that suit the needs of wheelchair users. This recommendation is supposed to be implemented at Gambir Station and other stations in
Indonesia to facilitate wheelchair users' mobility to access Gambir Station independently and without obstacles.

\section{MATERIAL AND METHOD}

\subsection{Wheelchair Mobility Problem}

Mobility facilities will determine how a person can move from one place to another. Non-disabilities can move vertically using stairs or ramps [7], but for wheelchair users, to be able to move vertically, they are very dependent onramps or elevators. Important things to consider in mobility issues are issues regarding travel routes that can be accessed by wheelchair users, surface slope, differences in surface levels, drainage, and texture of road surfaces accessed by wheelchair users [8].

\subsection{Corridor or Pedestrian Path}

The pedestrian path serves to walk or use a wheelchair. Pedestrian paths should be able to make users move safely, efficiently, comfortably, and without obstacles [9]. Things to consider in designing a pedestrian path are that the pedestrian path's surface conditions must be stable, durable, have a smooth texture but not slippery. The minimum width of the pedestrian path is $92 \mathrm{~cm}$ (without railing) or $112 \mathrm{~cm}$ (with railing) to be passed by one wheelchair user and 184 $\mathrm{cm}$ (without railing) or $204 \mathrm{~cm}$ (with railing) to be passed by two wheelchair users. The pedestrian path's maximum 
slope is 2 degrees (wide side) and 5 degrees (long side). If there is a drainage path in the pedestrian path, then the drainage path should be designed in a pattern perpendicular to the pedestrian path.

\subsection{Parking Area and Passenger Loading}

The parking area is the area used for parking, while the area for pick-up and drop-off passengers is called Passenger Loading Zones [10]. Parking areas for disabilities must be as close as possible to the building entrance with a maximum distance of 60 meters [11]. Disability parking lots must have a minimum width of $370 \mathrm{~cm}$ for single parking and $620 \mathrm{~cm}$ for double parking and are connected directly to the ramp or the building's path. For passenger loading zones, they must have a minimum area of $360 \times 600 \mathrm{~cm}$.

\section{METHODS}

This research uses a qualitative-phenomenological methodology approach to describe and explore individuals' life experiences and find out how subjective and objective individual experiences are with these phenomena [12]. In this study, researchers conducted data collection with participants-observation and interviews with Gambir Station management, wheelchair users, and conditioned respondents. The results of observations obtained by the author will be processed and analyzed using the directed content analysis approach based on theory or findings from previous studies that are relevant to the research topic and then compared with the results of observations [13]. According to the analysis results, the problem will be synthesized into a mobility facility recommendation that accommodates wheelchair users' needs.

\section{FINDING AND DISCUSSION}

\subsection{Parking Area and West Corridor}

The parking area is located on the west side of the Gambir Station main building (see figure 1). Gambir Station has provided two disability parking lots that are marked with different symbols of disability and floor surface color. Nonetheless, this parking lot is only $230 \times 450 \mathrm{~cm}$, while the minimum standard for disability parking lots is $370 \mathrm{x}$ $600 \mathrm{~cm}$ for single parking and $620 \times 500 \mathrm{~cm}$ for double parking. This parking lot also does not yet have a circulation area for wheelchair users. The parking lot's location is 11.7 $\mathrm{m}$ from the west entrance and is directly connected to the western corridor.

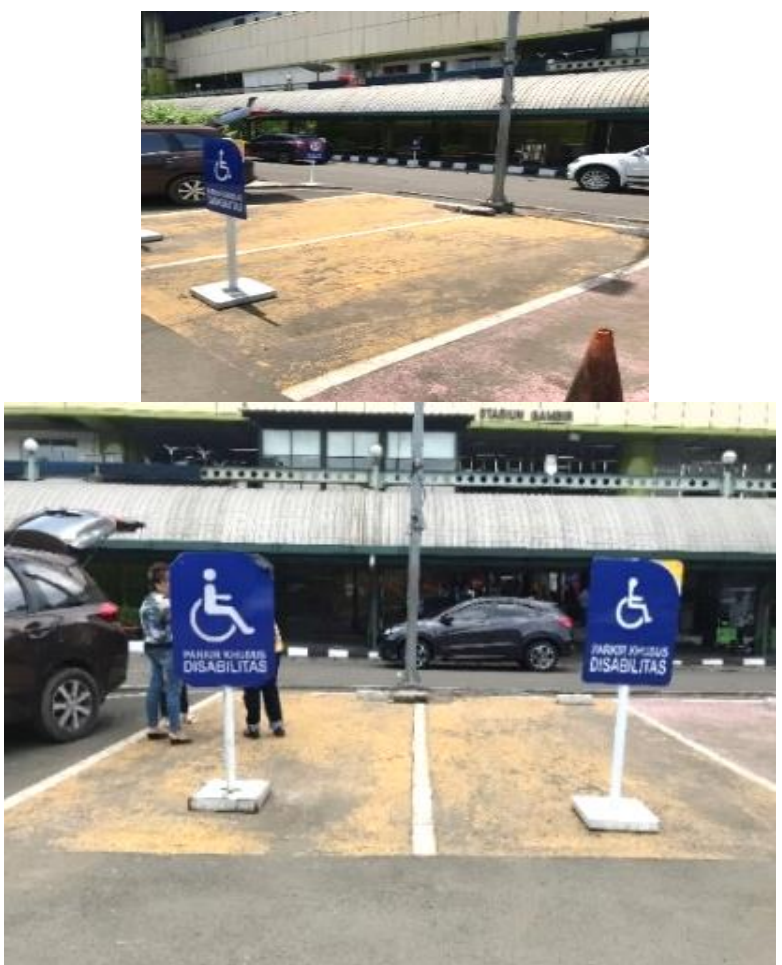

Figure 1. Existing photo of disability parking area [6]

Ideally, the disability parking lot has an appropriate area, which is $370 \times 600 \mathrm{~cm}$ for single parking and $620 \times 550 \mathrm{~cm}$ for double parking, which has a $120 \mathrm{~cm}$ wide circulation path. In the recommended parking area, the researchers designed a disability parking lot (priority parking) of three, assuming $2 \%$ of the total available parking lot. Researchers designed each parking lot of $230 \times 600 \mathrm{~cm}$ with an additional $160 \mathrm{~cm}$ that serves as a circulation area for wheelchair users. The parking lot also has a marker on the floor colored blue with a disability symbol and a signboard that reads "PARKING PRIORITY." The parking area has a higher elevation than the main road, so researchers provide a curb ramp with 5 degrees and a zebra crossing (Figure 2).

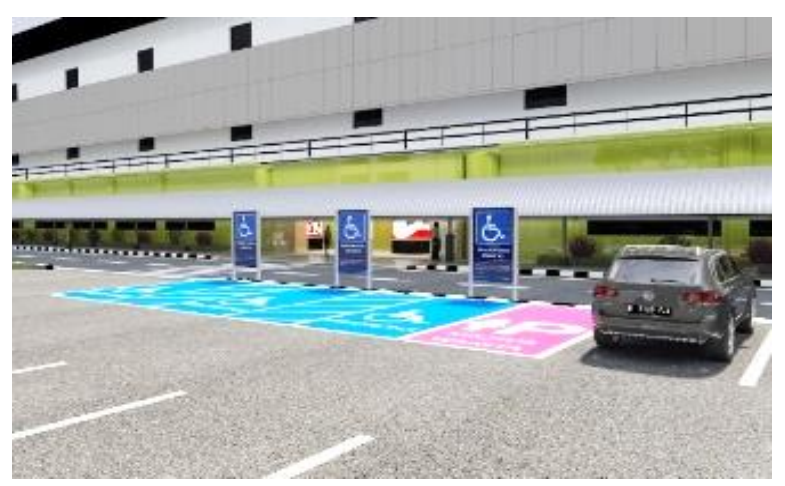



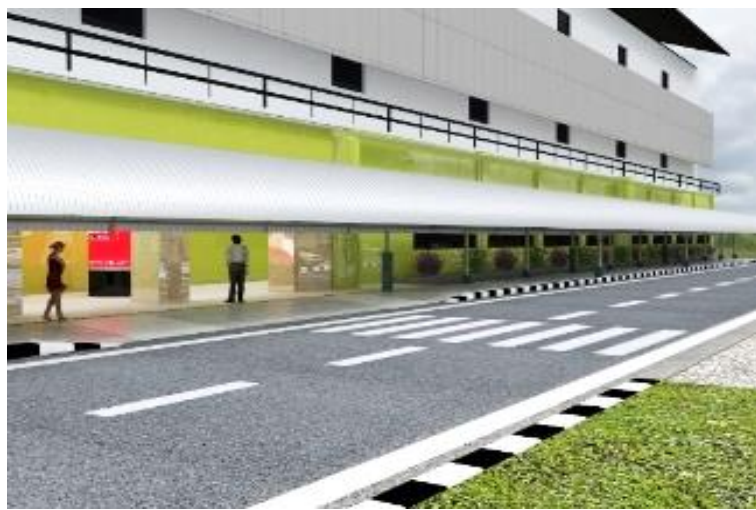

Figure 2. Illustration of parking area recommendation

The western corridor has a width of $340 \mathrm{~cm}$ with a surface slope (width) of 3 degrees, where the maximum slope (width) of the ideal pedestrian path surface is 2 degrees. This western corridor uses a paving block as a flooring material (Figure 3). This material is not suitable for wheelchair users because it has a rough and uneven texture, making wheelchair users need more effort to access the corridors.

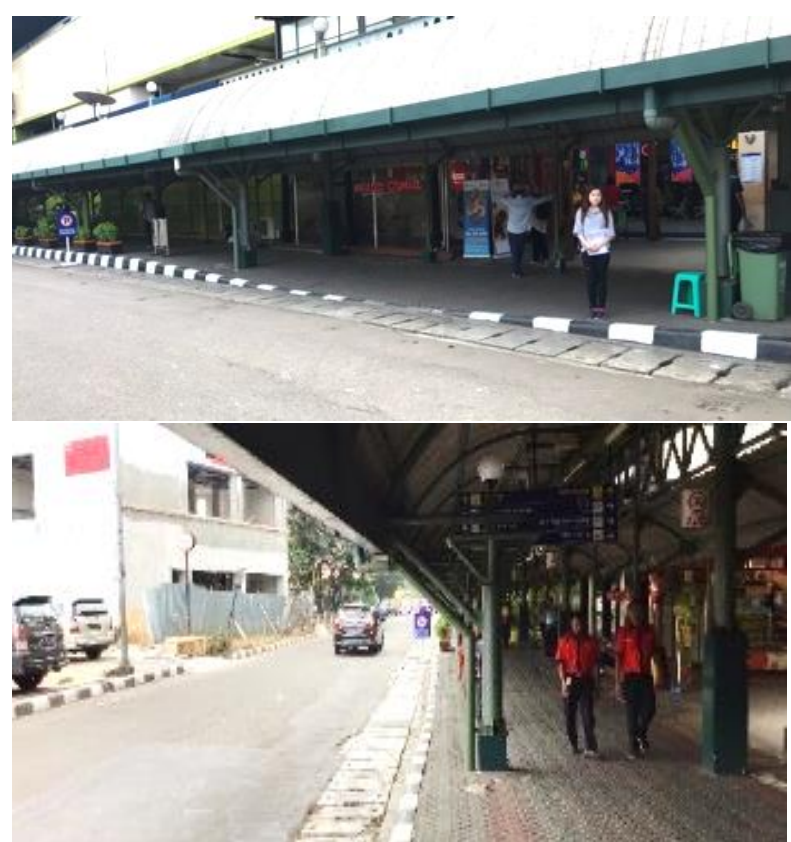

Figure 3. Existing photo of the western corridor [6]

The western corridor's recommendation is to replace the paving block with other material that has smoother but more durable and is not slippery when exposed to rain, i.e., using unpolished homogenous tiles. In the area that connects the road (zebra crossing) to the building (Figure 5), the researchers recommend a curb ramp with a width of 1400 $\mathrm{cm}$ and a slope of 5 degrees. In the edge area of the curb ramp, a yellow combination of black markings is given as a boundary marking of the curb ramp (Figure 4).

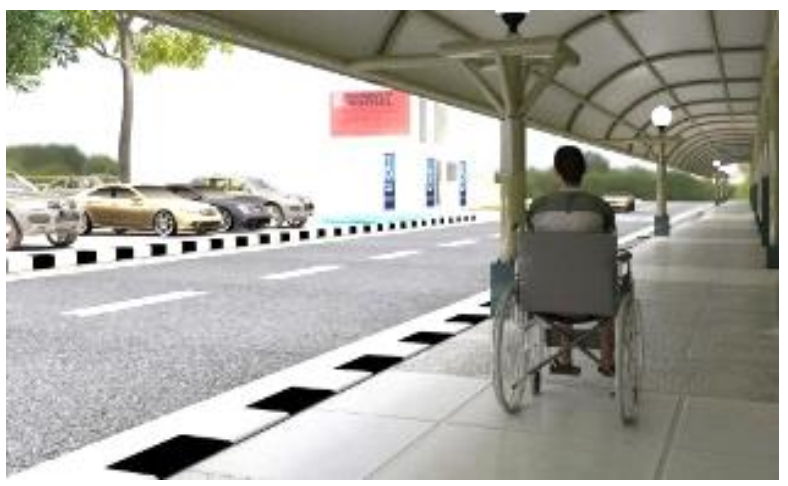

Figure 4. Illustration of western corridor recommendation

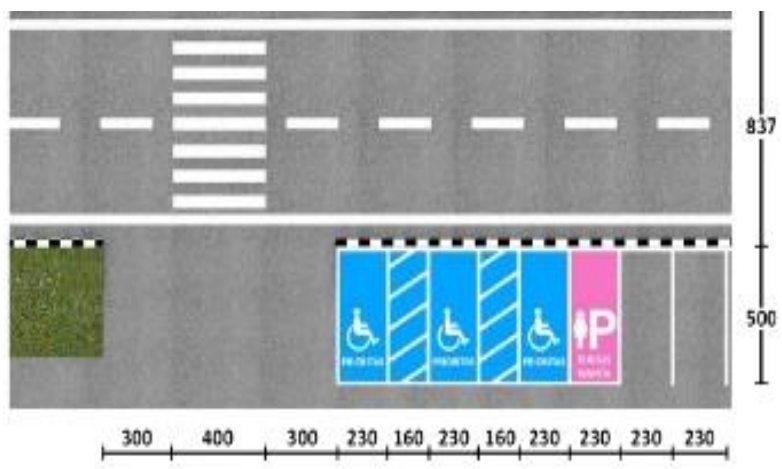

Figure 5. The zebra cross and dimension of the parking area and western corridor

\subsection{Passenger Loading Zones and East Corridor}

The loading zones Passenger Area (after this referred to as PLZ) is located on the east side of Gambir Station's main building. PLZ area has $250 \mathrm{~cm} \times 790 \mathrm{~cm}$, which should have a minimum area of PLZ is $360 \times 600 \mathrm{~cm}$. This area is directly related to the eastern corridor. The eastern corridor has a $295 \mathrm{~cm}$ width with a surface slope reaching 2 degrees that have met the standard. The floor in the eastern corridor uses the same paving block as the western corridor. The use of this material is not suitable for wheelchair users because it will make wheelchair users use more effort to be able to access the area. PLZ and the curb ramp connects the eastern corridor (Figure 6 and 7). This curb ramp has a width of 120 $\mathrm{cm}$ with a length of $120 \mathrm{~cm}$ and 12 degrees. Whereas ideally, the maximum slope of the curb ramp for the outside area is a maximum of 5 degrees.

Researchers recommend PLZ with a width of $360 \mathrm{~cm}$ and $1400 \mathrm{~cm}$ to be used by two cars concurrently. To access the eastern corridor and main building, the PLZ is connected with a curb ramp, $1400 \mathrm{~cm}$ wide, with a slope of 5 degrees. Reducing the curb ramp's slope will reduce the effort spent by wheelchair users. The use of paving blocks should be replaced with other materials that have smoother but more durable and is not slippery when exposed to rain, i.e., using unpolished homogenous tiles (Figure 8, 9, 10). 


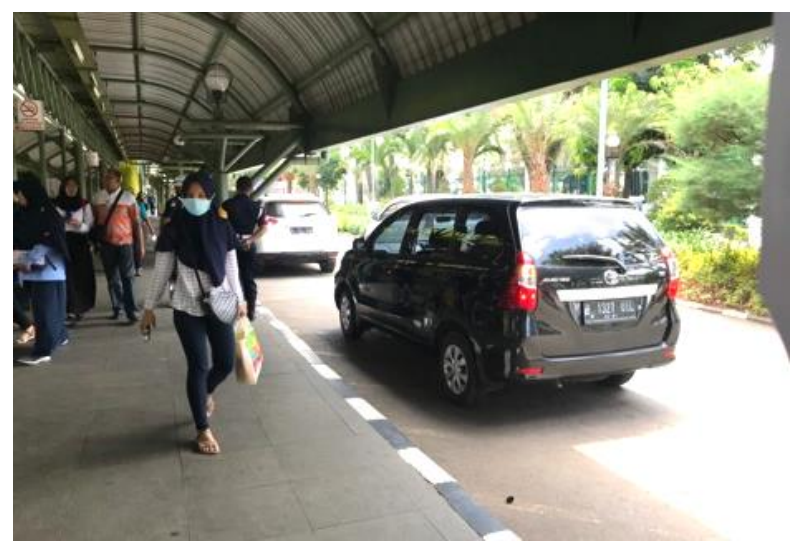

Figure 6. Photo of the eastern corridor and PLZ [6]

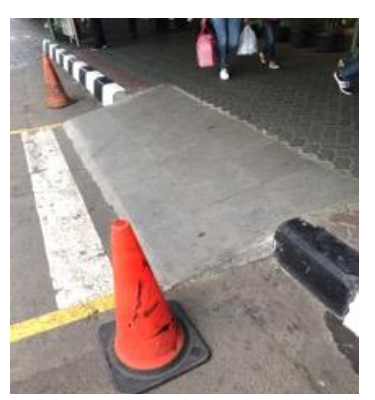

Figure 7. Photo of the curb ramp [6]

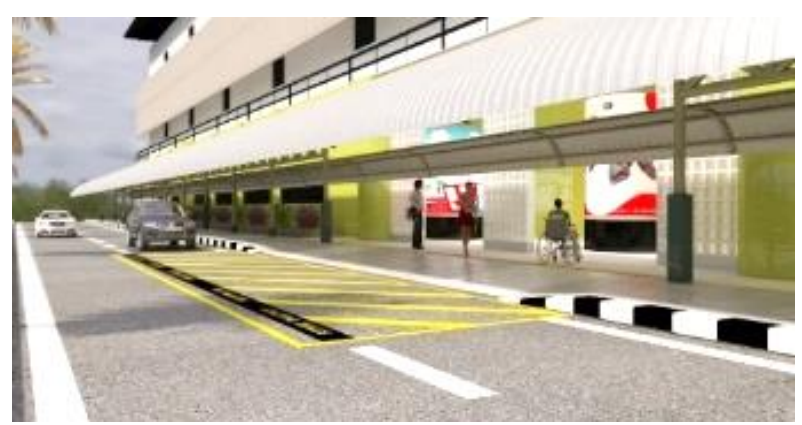

Figure 8. Illustration of PLZ

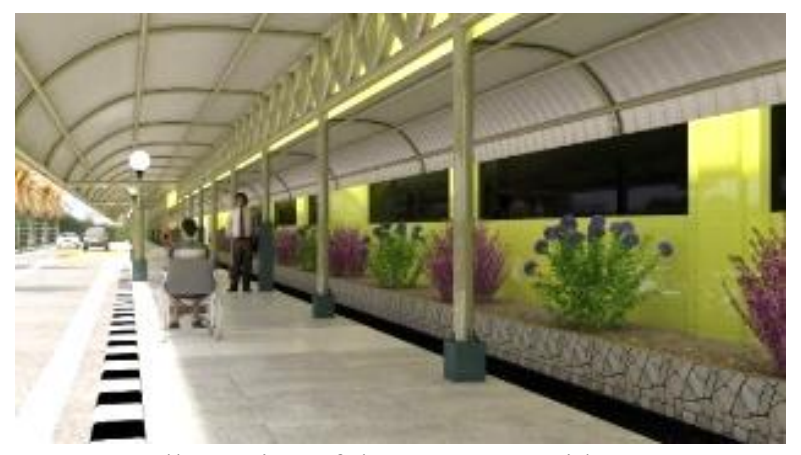

Figure 9. Illustration of the eastern corridor
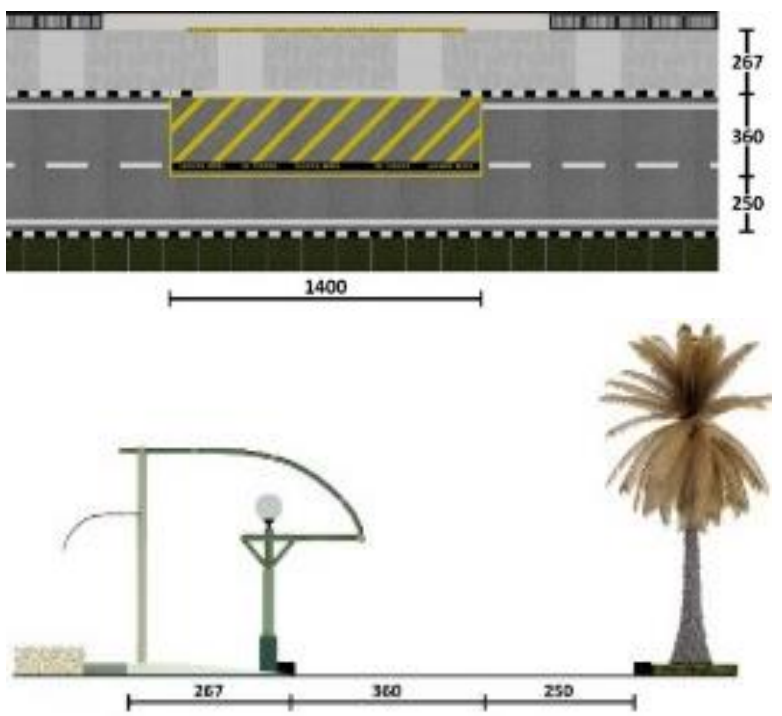

Figure 10. Illustration of PLZ dimensions and eastern corridors

\subsection{Vertical Circulation}

Gambir Station has stairs, two escalators, and two elevators that serve as vertical transportation. The elevator is the only vertical transportation that can be used by wheelchair users. The elevators are located near the north exit, where elevator A functions to get to platforms 3 and 4, while elevator B serves to get to platforms 1 and 2 . The two elevators at Gambir Station have the same interior dimensions, which are $180 \times 160 \mathrm{~cm}$. The size of the elevators at Gambir Station has met the minimum requirements of $140 \times 140 \mathrm{~cm}$. However, the height of the elevator's outer panel is $110 \mathrm{~cm}$, and the height of the inner panel is 113 to $142 \mathrm{~cm}$, higher than the standard, which is a maximum of $90 \mathrm{~cm}$. This elevator has reflective material and is equipped with handrails on all three sides of the wall.

According to the above analysis, this elevator follows the needs of wheelchair users. However, it needs some adjustments, such as the elevator panel's height to be easier accessed by wheelchair users. Another problem that the researchers found was how wheelchair users accessed the platform area when one of the elevators was under repair/maintenance. The nonexistence of alternative vertical transportation causes this problem. Accordingly, researchers recommend utilizing escalators at Gambir Station to improve their specifications to be wheelchair accessible escalators such as those available at train stations in Japan Station (Figure 11), or the management can use the existing stairs to be added to the stairway lift (Figure 12). It aims as alternative vertical transportation so that wheelchair users can still access the platform area while the elevator is under repair/maintenance. 

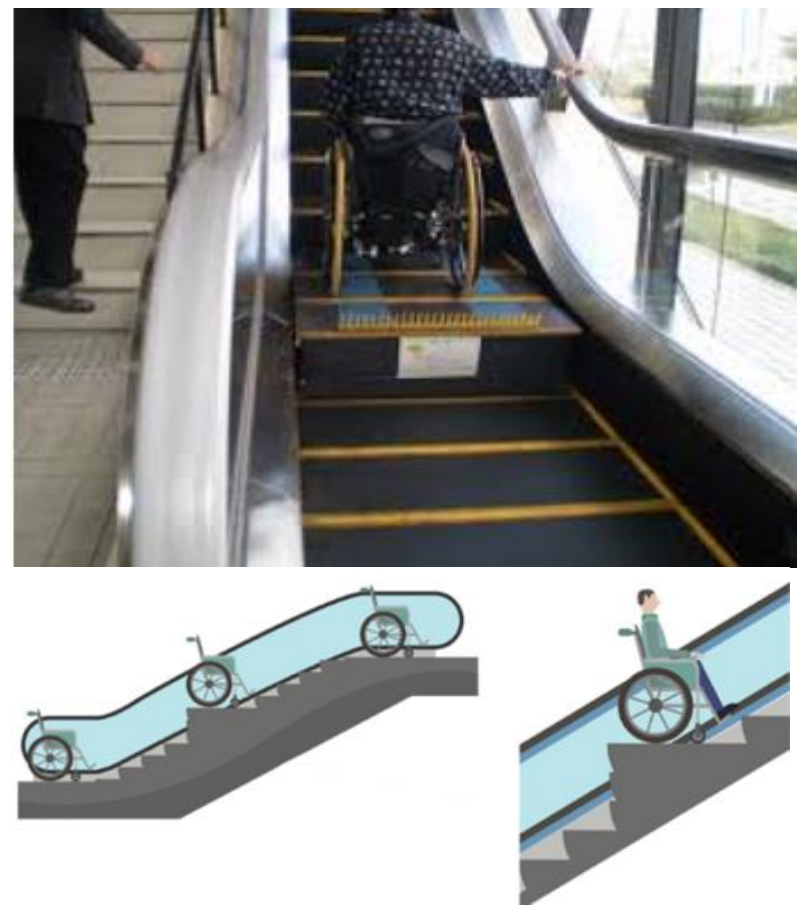

Figure 11 Wheelchair accessible escalator Source: http://www.japan-accessible.com, accessed on April $27^{\text {th }}, 2020$
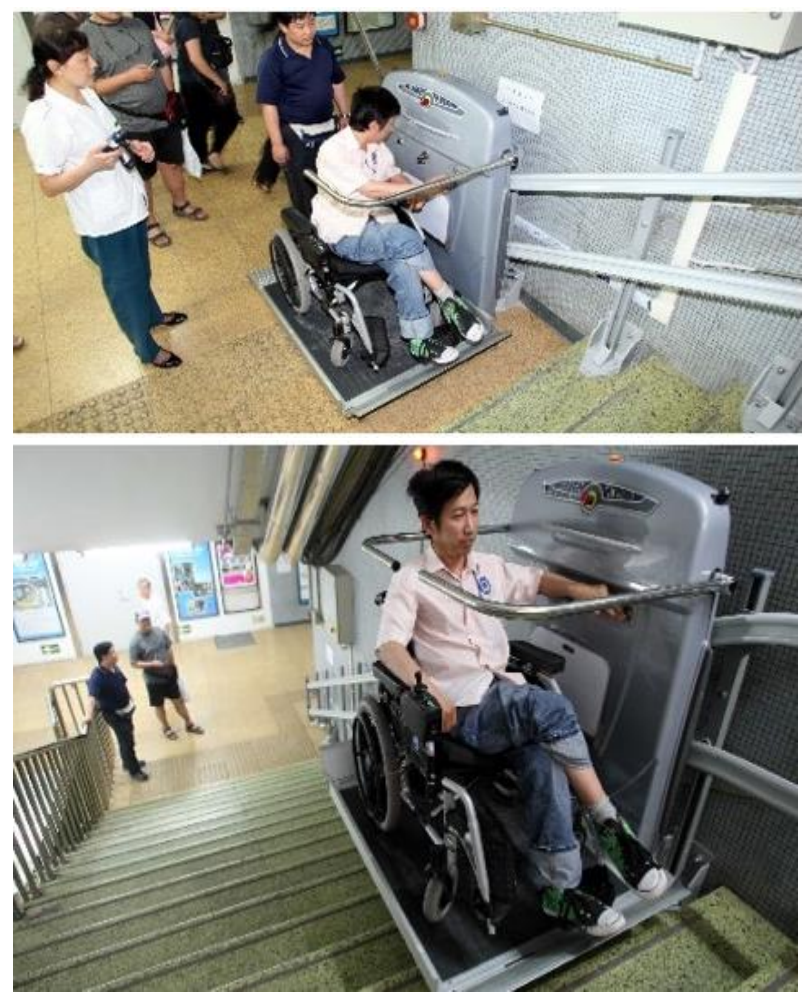

Figure 12 Stairway lift in Chegongzhuan, Beijing Metro

Source: http://www.china.org.cn, accessed on May $10^{\text {th }}$, 2019

\section{CONCLUSIONS}

According to the research results, the researchers concluded that some of the mobility facilities at Gambir Station did not meet wheelchair users' needs. Some of these facilities are disability parking areas, passenger loading zones, corridors, and vertical circulation. Consequently, researchers provide several design recommendations, as described in the analysis. The suggestions given follow the needs and characteristics of wheelchair users so that they can comfortably and safely access all the facilities at Gambir Station without experiencing obstacles.

\section{ACKNOWLEDGMENT}

We gratefully thank Kemenristekdikti for supporting this research through a thesis grant. We thank Mr. Tri Eko Yuwono as the human resources division of DAOP 1 Jakarta and Mr. Iwan Junaidi as head of Gambir Station customer service for their support in the data collection and permission to survey at Gambir Station.

\section{REFERENCES}

[1] T. Savill, J. Stone, C. Venter, and D. Maunder, "Improving access to transport in developing countries," Municipal Engineer, vol. 156, no. 2, pp. 149-153, 2003.

[2] J. Tamba, "Exploring The Accessibility and Facility in Railway Station Used by Persons with Disabilities: An Experience From Kebayoran Railway Station, Jakarta," Indonesian Journal of Disability Studies (IJDS), vol. 5, no. 1, pp. 37-46, 2018.

[3] William, E. Supriyatna and F. Lianto, "Exploring Gambir Station by Wheelchair," in Tarumanagara International Conference on The Applications of Social Science \& Humanities (TICASH 2019), Jakarta, 2019.

[4] S. Goldsmith, Designing for Disabled, New York: Routledge, 2011.

[5] N. N. Zhe and K. M. Christensen, "Access to urban transportation system for individuals with disabilities," IATSS Research, vol. 41, no. 2, pp. 66-73, 2017.

[6] R. L. Mace, R. J. Pace, L. C. Young, and K. Olander, A Planning Guide for Making Temporary Events Accessible to People With Disabilities, Washington: ADA National Network, 2015. 
[7] J. W. Cresswell, Penelitian Kualitatif \& Desain Riset: Memilih di Antara Lima Pendekatan, Yogyakarta: Pustaka Pelajar, 2015.

[8] P. Roberts and J. Babinard, "Transport Strategy to Improve Accessibility in Developing Countries," World Bank Group, Washington DC, 2004.

[9] W. H. Organization, "Summary World Report on Disability,” WHO Publications, Geneva, 2011.

[10] S. M. Adioetomo, D. Mont and Irwanto, "Person with Disabilities in Indonesia: Empirical Facts and Implications for Social Protection Policies," Lembaga Demografi Fakultas Ekonomi Universitas Indonesia, Jakarta, 2014.

[11] M. Damayanti and F. Sabiq, "Implementation of Public Facilities and Disability Treatments: A Comparison Between Indonesia and Malaysia," Advances in Social Science, Education and Humanities Research, vol. 153, no. 1, pp. 11-15, 2017.

[12] L. Cameron and D. C. Suarez, "Disability in Indonesia: What can we learn from the data?," Monash University, Melbourne, 2017.

[13] H. Wennberg, C. Hydén and A. Ståhl, "Barrier-free outdoor environments: Older peoples' perceptions before and after implementation of legislative directives," Transport Policy, vol. 7, no. 6, pp. 464-474, 2010 .

[14] K. Lucero-Duarte, E. d. 1. Vega-Bustillos, F. LópezMillán, and S. Soto-Félix, "Anthropometric data of adult wheelchair users for Mexican population," in IEA 2012: 18th World Congress on Ergonomics - Designing a sustainable future, Sonora, 2012.

[15] A. A. Dingley, B. Burkett and D. B. Pyne, "Relationships Between Propulsion and Anthropometry in Paralympic Swimmers," International Journal of sports physiology and performance, vol. 10, no. 8, p. 978-985, 2015. 